\title{
Delayed saccadic eye movements in glaucoma
}

This article was published in the following Dove Press journal:

Eye and Brain

26 November 2012

Number of times this article has been viewed

\section{Raageen Kanjee' \\ Yeni H Yücel ${ }^{1,2}$ \\ Martin J Steinbach ${ }^{3,4}$ \\ Esther G González ${ }^{3,4}$ \\ Neeru Gupta ${ }^{1,2,5}$ \\ 'Ophthalmology and Vision \\ Sciences, Laboratory Medicine and Pathobiology, St Michael's Hospital, University of Toronto, ${ }^{2}$ Keenan Research Centre at the Li Ka Shing Knowledge Institute of St Michael's Hospital, ${ }^{3}$ Toronto Western Hospital, University Health Network, ${ }^{4}$ Centre for Vision Research, York University, ${ }^{5}$ Glaucoma and Nerve Protection Unit, St Michael's Hospital, Toronto, ON, Canada}

Correspondence: Neeru Gupta St Michael's Hospital, 30 Bond Street, ON, M5B IW8, Canada

$\mathrm{Tel}+\mathrm{I} 4168645444$

$\mathrm{Fax}+$ I 4168645208

Email guptan@smh.ca Cardinal Carter Wing, 8-072, Toronto,

Purpose: To determine whether saccadic eye movements are altered in glaucoma patients.

Patients and methods: Sixteen patients with glaucoma and 21 control subjects were prospectively studied. Patients participated in a pro-saccade step task. Saccades were recorded using a noninvasive infrared oculometric device with head-mounted target projection. Medians of saccade reaction time, duration, amplitude, and peak velocity; frequency of express saccades; and percentage of trials with direction error were recorded. $t$-tests were used to compare the glaucoma and age-matched control groups. A correlation analysis of saccade parameters with visual field loss was also performed.

Results: Median saccade reaction times were significantly prolonged in glaucoma patients compared with controls $(220.9 \pm 49.02 \mathrm{~ms}$ vs $192.1 \pm 31.24 \mathrm{~ms}$; $t$-test: $P=0.036)$. Median duration, median amplitude, and median peak velocity of saccades did not show significant differences between glaucoma and control groups $(P>0.05)$. Frequency of express saccades was significantly decreased in glaucoma patients compared with controls $(1.75 \pm 2.32$ vs $7.0 \pm 6.99$; $t$-test: $P=0.007)$. Saccade parameters in glaucoma patients showed no significant correlation with visual field loss.

Conclusion: Saccadic eye movements are significantly delayed in patients with early, moderate, or advanced glaucoma. Determination of median saccade reaction time may offer a novel functional test to quantify visual function in glaucoma patients. Further studies are needed to determine pathological processes implicated in delayed initiation of saccades, and to assess whether alteration of saccades affects daily activities in glaucoma patients.

Keywords: visual field, latency, visual dysfunction, brain, superior colliculus, quality of life

\section{Introduction}

Glaucomatous optic neuropathy is a leading cause of irreversible blindness worldwide. ${ }^{1}$ Loss of sight in glaucoma is caused by death in retinal ganglion cells, ${ }^{2}$ and involves visual functions such as form, motion, and color. ${ }^{3-5}$ Functional tests for the diagnosis of glaucoma and for the assessment of progression are processed by retinal ganglion cells that project to the lateral geniculate nucleus, ${ }^{6}$ a relay station to the primary visual cortex. In glaucoma, neurodegeneration in this major retino-geniculo-cortical pathway has been demonstrated. ${ }^{7-15}$

The effect of glaucoma on other visual functions such as eye movements that are controlled by alternative visual pathways is not well studied. Saccades are rapid eye movements that redirect the fovea to visual targets, such as a suddenly appearing visual stimulus. ${ }^{16}$ They are generated by a complex network of brain structures, including the retino-tectal pathway. ${ }^{17}$ Saccades can be measured precisely with reliable parameters such as saccade reaction time, saccade duration, ${ }^{18}$ amplitude, ${ }^{19,20}$ and peak velocity. ${ }^{21,22}$ 
Studies of these saccade parameters are used to assess the integrity of the saccade-generating neural network in various brain diseases. ${ }^{23-28}$ In addition, saccade parameters such as increased saccade reaction time are altered in various optic nerve pathologies affecting the nerve fibers that convey visual signals to the saccade-generating network. ${ }^{29,30}$ We hypothesize that eye movements may provide another functional marker of injury in glaucoma. The aim of this study was to determine whether saccadic eye movements are altered in glaucoma patients.

\section{Material and methods}

After study approval by St Michael's Hospital Research Ethics Board, informed consent was obtained from glaucoma and age-matched participants between the ages of 40 and 80 years. Patients with primary open-angle glaucoma and a history of uncontrolled intraocular pressure $(n=16)$ were prospectively recruited from the practice of a glaucoma specialist (NG). Glaucoma was defined by characteristic optic nerve head findings with corresponding visual field changes assessed by white on white automated perimetry. Vision loss was estimated by the sum of mean deviations of right and left visual fields. Exclusion criteria included other nonglaucomatous eye disease, monocularity, incisional eye surgery within a month, central acuity of less than 20/50 OU, history of neurological disease, and use of psychotropic medications known to affect saccade velocity. ${ }^{31}$ Control subjects $(n=21)$ were recruited from visitors or personnel working at the institution and from relatives of patients. All control subjects had normal eye examinations. Glaucoma and agematched control subjects underwent full eye examinations. Age and visual acuity were not different between glaucoma and age-matched controls (Tables 1-3). Mean ages of glaucoma patients and controls were $63.2 \pm 8.70$ years and $60.9 \pm 8.13$ years, respectively $(P=0.42)$. Glaucoma patients showed minimal to advanced visual field loss (Table 3 ).

Table I Demographics ${ }^{\mathrm{a}}$

\begin{tabular}{llll}
\hline & Control & Glaucoma & Significance \\
\hline Number & 21 & 16 & \\
Percentage female & $57 \%$ & $44 \%$ & \\
Age (years) & $60.9(8.05)$ & $63.2(8.70)$ & $P=0.42$ \\
Acuity OD & $0.737(0.213)$ & $0.700(0.212)$ & $P=0.6 \mathrm{I}$ \\
Acuity OS & $0.693(0.227)$ & $0.616(0.254)$ & $P=0.34$ \\
\hline
\end{tabular}

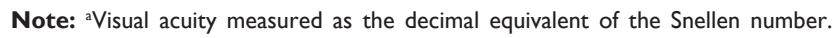
Values in parentheses are standard deviations. Significance $P$-values represent the outcome of an independent-samples $t$-test.

Abbreviations: OD, right eye; OS, left eye.
Table 2 Participant summary data for controls

\begin{tabular}{|c|c|}
\hline Age (years) & Gender \\
\hline \multicolumn{2}{|l|}{ Control } \\
\hline 46 & Male \\
\hline 50 & Female \\
\hline 53 & Female \\
\hline 56 & Male \\
\hline 56 & Male \\
\hline 56 & Female \\
\hline 57 & Male \\
\hline 57 & Male \\
\hline 57 & Female \\
\hline 58 & Female \\
\hline 58 & Female \\
\hline 61 & Female \\
\hline 61 & Female \\
\hline 62 & Female \\
\hline 63 & Female \\
\hline 65 & Male \\
\hline 68 & Female \\
\hline 70 & Male \\
\hline 71 & Female \\
\hline 74 & Male \\
\hline 79 & Male \\
\hline
\end{tabular}

\section{Eye movement recordings}

All glaucoma and control participants were tested under similar conditions under constant observation. Participants were seated $1.5 \mathrm{~m}$ away from an evenly lit wall with luminance measured at $500 \mathrm{~cd} / \mathrm{m}^{2}$ (Minolta Luminance Meter LS-100, Osaka, Japan). A noninvasive infrared oculometric device with a head-mounted system of low-power lasertarget projections (saccadometer) (Ober Consulting, Poznan,

Table 3 Participant summary data for glaucoma

\begin{tabular}{lll}
\hline Age (years) & Gender & $\begin{array}{l}\text { Total mean } \\
\text { deviation (dB) }\end{array}$ \\
\hline Glaucoma & Male & 0.07 \\
72 & Male & -1.01 \\
63 & Male & -7.68 \\
77 & Female & -9.01 \\
62 & Female & -10.54 \\
57 & Male & -11.19 \\
68 & Female & -11.68 \\
61 & Female & -11.89 \\
70 & Female & -14.1 \\
71 & Male & -18.62 \\
56 & Male & -20.29 \\
59 & Male & -21.64 \\
54 & Female & -23.16 \\
60 & Male & -26.56 \\
42 & Female & -27.21 \\
69 & Male & -36.82 \\
70 & &
\end{tabular}


Poland) projected three high-contrast $\left(13 \mathrm{~cd} / \mathrm{m}^{2}\right)$ discs subtending $0.1^{\circ}$ in diameter, at $0^{\circ}, 10^{\circ}$ left, and $10^{\circ}$ right, along the frontal plane at eye level. Viewing and recording were performed binocularly. Prior to proceeding with testing, all participants were required to report clearly seeing the red stimuli located at $0^{\circ}, 10^{\circ} \mathrm{left}$, and $10^{\circ}$ right. Calibrations were made for both left and right stimuli under binocular viewing.

After a random foreperiod (500-1000 ms), the central fixation point was extinguished, and a randomly chosen $10^{\circ}$ left or $10^{\circ}$ right stimulus was projected. There were no gaps or overlaps, and the stimuli remained projected until either the participant performed a saccade or $2000 \mathrm{msec}$ had elapsed. Each session consisted of 200 trials, measured over the course of 15 minutes. Saccade reaction time, duration, amplitude, peak velocity, and direction were recorded with a sampling rate of $1 \mathrm{kHz}$ and a linear range within $7 \%$ for up to $\pm 30^{\circ}$ (Ober Consulting). ${ }^{23}$ Blinks and head movements were automatically excluded by the Latency Meter Version 4.9 software (Ober Consulting), and analysis was performed on saccades made toward the stimulus. Trials with saccade reaction times between $50 \mathrm{~ms}$ and $600 \mathrm{~ms}$ were analyzed, removing anticipatory saccades $(<50 \mathrm{~ms})$ and latencies due to inattention $(>600 \mathrm{~ms}) .{ }^{22,24-26}$ Trials with saccade reaction times between $50 \mathrm{~ms}$ and $100 \mathrm{~ms}$ were defined as express saccades, ${ }^{19,32-36}$ and their frequency was counted. Trials with direction error were analyzed separately.

\section{Statistical analysis}

Statistical analysis was performed using SPSS Version 14.0 (SPSS Inc, Chicago, IL) and SAS 9.2 (SAS Institute Inc, Cary, NC) with $\alpha$ level set at 0.05 . Medians of saccade reaction time, duration, amplitude, and peak velocity, and frequency of express saccades were calculated. These variables in the glaucoma group were compared with age-matched controls using independent-samples $t$-tests. A $P$-value less than 0.05 was considered statistically significant. Bivariate correlations of the visual field loss (as measured by the sum of mean deviations of right and left visual fields) and various saccade variables were calculated using the Pearson correlation coefficient.

\section{Results}

Figure 1 shows a series of saccade recordings and histograms of saccade reaction times of representative glaucoma and control subjects. Saccade reaction times were prolonged in glaucoma patients compared with controls (Figure 2). Median saccade reaction time was significantly increased in glaucoma patients compared with controls (220.9 $\pm 49.02 \mathrm{~ms}$ vs $192.1 \pm 31.24 \mathrm{~ms}$; $P=0.036$ ) (Figure 3). Median duration, median amplitude, and median peak velocity were not statistically different between groups $(54.7 \pm 5.16 \mathrm{~ms}$ vs $52.8 \pm 4.45 \mathrm{~ms}, P=0.25$; $10.4 \pm 1.88^{\circ}$ vs $9.5 \pm 1.69^{\circ}, P=0.12 ; 349.4 \pm 72.01^{\circ} / \mathrm{s}$ vs $345.0 \pm 83.41^{\circ} / \mathrm{s}, P=0.87$ ) (Table 4).

There was a significant reduction in the number of express saccades in the glaucoma patients compared with controls $(1.75 \pm 2.32$ vs $7.0 \pm 6.99 ; P=0.007)$. The percentage of direction errors between the glaucoma and control groups was not statistically different (1.72 $\pm 1.82 \%$ vs $3.2 \pm 5.89 \%$; $P=0.34$ ) (Table 4), and neither were direction errors significantly correlated with the degree of visual field loss in the glaucoma group $(P=0.54)$.

Median saccade reaction time, median duration, median amplitude, and median peak velocity were not statistically correlated with the degree of visual field loss $(P=0.64$, $P=0.25, P=0.14$, and $P=0.38$, respectively).

\section{Discussion}

This is the first study to demonstrate that saccade latencies are affected in glaucoma. Glaucoma patients were slower to initiate the saccade compared with age-matched controls. Normal saccade reaction times in control subjects in our study are consistent with previous work. ${ }^{25,27,34}$

The fact that other saccade parameters such as duration, amplitude, and peak velocity are not altered suggests that patients were able to detect the targets located at $10^{\circ}$ to the right and to the left of the fixation point, and that once the saccades were initiated, the accuracy and the motor characteristics of the saccades were not significantly affected. Therefore, the glaucomatous pathological process seems to alter mainly the initiation of saccades that involve visual input as well as a complex saccade-generation network.

The neural network underlying saccade generation involves a multitude of structures, including superior colliculus, areas of the frontal lobe, and the basal ganglia. ${ }^{17}$ Visual input to the saccade-generating network is provided by a specific subpopulation of retinal ganglion cells that project directly to superior colliculus, ${ }^{6,37}$ and indirect visual input via the primary visual cortex also projects to the superior colliculus. ${ }^{38}$ In view of the fact that delayed saccades have been described in various optic nerve diseases, ${ }^{29,30}$ the delayed saccades observed in patients with glaucomatous optic neuropathy are likely due to damage to retinal ganglion cells that provide direct retinal input to superior colliculus ${ }^{6}$ and/or that drive the visual information through the visual cortex. ${ }^{38,39}$ It is interesting to note that delayed saccades are found in patients 

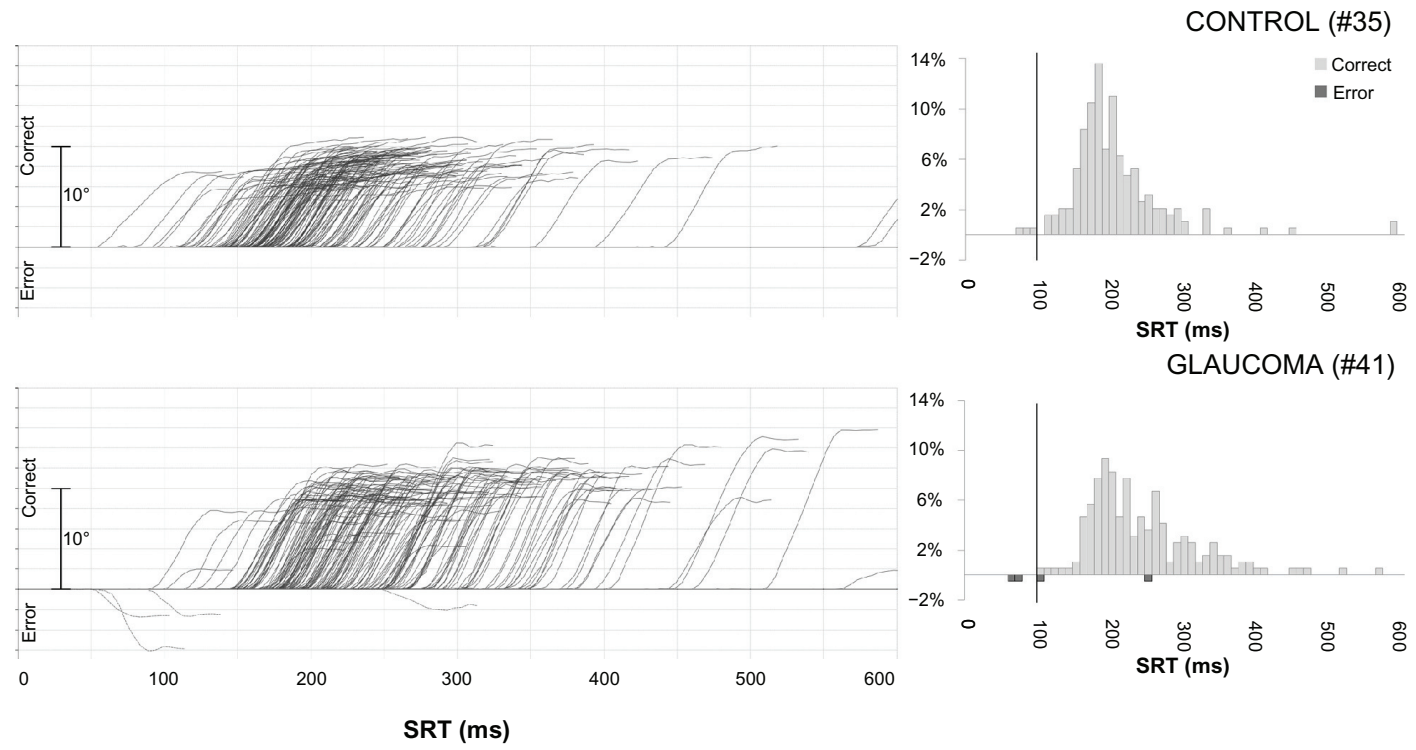

Figure I Traces of individual saccades for two subjects (left) and histograms of corresponding reaction times (right). ${ }^{\mathrm{a}}$

Notes: ${ }^{2}$ The left column shows eye position (in degrees) as a function of time (in ms) after the onset of the stimulus. Traces above the x-axis show saccades made in the correct direction for the stimulus, whereas those below show direction errors. Each curve represents a single saccade. The right column shows histograms of reaction times for the two subjects (percentage of total responses on the $y$-axis, saccade reaction times [SRT] in ms on the $x$-axis). Light bars above the $x$-axis represent saccades made in the correct direction, whereas dark bars below the $\mathrm{x}$-axis represent direction error. Data points to the left of the bolded vertical line represent express saccades (saccade reaction times $<100 \mathrm{~ms})$.

with mild visual field loss, as well as in advanced cases. It is not yet known whether the increased latency of nerve conduction in the retino-geniculate pathway ${ }^{40,41}$ and/or the decreased amplitude of retinal ganglion cell response ${ }^{42}$ reported in some glaucoma patients contribute to delayed saccades in glaucoma patients. Further studies are needed to determine whether the retinal ganglion cells conveying visual information to the saccade-generation network are affected in glaucoma.

The superior colliculus is critical to saccade generation, with a role in both visual and motor components. ${ }^{17}$ In addition to its sensory role as a visual information-recipient structure arranged in a retinotopic fashion, it plays an important role in

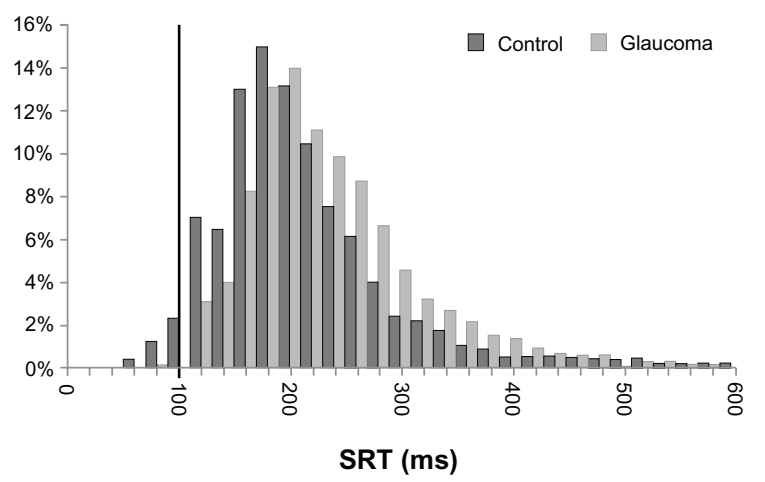

Figure 2 Saccade reaction times (SRT). ${ }^{\mathrm{a}}$

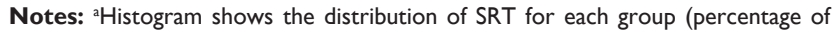
total responses on the $y$-axis, and in ms on the $x$-axis). Dark bars represent data from control subjects; light bars represent data from glaucoma patients. Data points to the left of the bolded vertical line at $100 \mathrm{~ms}$ represent express saccades. influencing saccade generation through its direct projection to the brainstem reticular formation, ${ }^{43}$ which, in turn, projects to oculomotor neurons. ${ }^{44}$ Ablation of superior colliculus in nonhuman primates leads to increased saccade reaction times and eliminates a subpopulation of express saccades. ${ }^{45}$ Interestingly, in addition to prolonged saccade reaction time, we noted a reduced frequency of express saccades in glaucoma. Investigations in nonhuman primate experimental glaucoma may help to determine whether the retinal ganglion

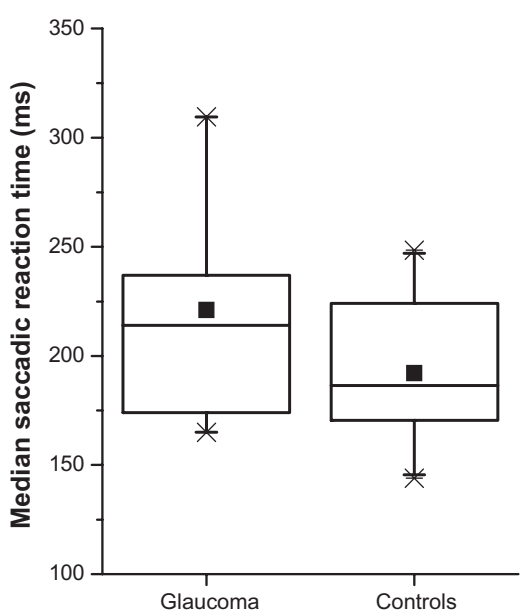

Figure 3 Box plots of median saccade reaction times per group. ${ }^{a}$

Notes: ${ }^{a}$ The horizontal bars across the boxes are the medians of the groups; small squares indicate group means. The boxes themselves delineate the 25 th percentile to the 75th percentile of each group, the "whiskers" indicate the 5th and 95th percentiles, and the " $X$ "s mark minima and maxima. 
Table 4 Saccade parameters in glaucoma and controls

\begin{tabular}{lllll}
\hline $\begin{array}{l}\text { Saccade } \\
\text { parameter }\end{array}$ & Control & Glaucoma & P-value & $t$-value \\
\hline $\begin{array}{l}\text { Median reaction } \\
\text { time (ms) }\end{array}$ & $192.1(31.24)$ & $220.9(49.02)$ & $P=0.036$ & $t=2.18$ \\
$\begin{array}{l}\text { Median } \\
\text { duration (ms) }\end{array}$ & $52.8(4.45)$ & $54.7(5.16)$ & $P=0.25$ & $t=1.17$ \\
$\begin{array}{l}\text { Median } \\
\left.\text { amplitude ( }{ }^{\circ}\right)\end{array}$ & $9.5(1.69)$ & $10.4(1.88)$ & $P=0.12$ & $t=1.57$ \\
$\begin{array}{l}\text { Median peak } \\
\text { velocity ( } / \mathrm{s})\end{array}$ & $345.0(83.4 \mathrm{I})$ & $349.4(72.01)$ & $P=0.87$ & $t=0.17$ \\
$\begin{array}{l}\text { Express saccades } \\
\text { frequency) }\end{array}$ & $7.0(6.99)$ & $1.75(2.32)$ & $P=0.007$ & $t=2.88$ \\
$\begin{array}{l}\text { Trials with } \\
\text { direction } \\
\text { error (\%) }\end{array}$ & $3.2(5.89)$ & $1.72(1.82)$ & $P=0.34$ & $t=0.97$ \\
\hline
\end{tabular}

cells and superior colliculus involved in the generation of saccades are, indeed, affected in glaucoma.

Few studies have looked at eye movements in glaucoma. Other types of gaze-shifting eye movements such as smooth pursuit have not yet been studied. Among the gaze-stabilizing eye movements, optokinetic nystagmus has been investigated and shown to exhibit characteristic differences in glaucoma patients as compared with controls, eg, in pursuit eye movement and optokinetic nystagmus elicitation tasks. ${ }^{46,47}$ Other studies have examined the eye movements of glaucoma patients as either pedestrians or drivers. Gaze behavior has been shown to differ in a group of glaucoma patients compared with controls when crossing a street, ${ }^{48}$ whereas eye-tracking data have shown changes in the pattern of eye movements performed by glaucoma patients compared with controls while viewing a video of a driving scene ${ }^{49}$ Further studies are needed to determine whether delayed saccades in glaucoma may contribute to these altered eye movements.

Certain pharmacological agents are known to alter saccade parameters. Patients on psychotropic medications, including benzodiazepines, antipsychotics, and anticonvulsants, which are known to decrease saccade velocity, ${ }^{31}$ were excluded in this study. This study shows that saccade reaction time is increased in glaucoma patients, and though topical treatment effects cannot be ruled out, no statistically significant difference in saccade reaction times $(P=0.42)$ was noted between glaucoma patients on topical $\beta$-blockers $(\mathrm{n}=8)$ compared with those who were not $(\mathrm{n}=8)$.

Glaucoma patients are known to be at increased risk for falls and motor vehicle collisions. ${ }^{50}$ These tasks are dependent on a person's ability to attend to and respond to visual stimuli. Further studies are needed to determine whether delayed saccades observed in glaucoma patients have functional implications and contribute to an increased risk for falls and motor vehicle collisions.

Overall, this study provides the first insight into saccade alterations in glaucoma. Further studies are needed to investigate the possible locations of neural damage in pathways and centers involved in saccades, to determine whether saccade changes correlate with disease development and/or progression, and to evaluate their possible functional impact in patients with glaucoma.

\section{Acknowledgments}

The authors would like to thank Joyce Lo and Lalaine Songalia for their excellent research assistance, and Barbara Thomson MSc for statistical analysis. This study was supported by the Glaucoma Research Society of Canada (NG, YY), Dorothy Pitts Fund (NG), and the University of Toronto CREMS program.

\section{Disclosure}

The authors report no conflicts of interest in this work.

\section{References}

1. Resnikoff S, Pascolini D, Etya'ale D, et al. Global data on visual impairment in the year 2002. Bull World Health Organ. 2004;82(11): 844-851.

2. Quigley HA. Neuronal death in glaucoma. Prog Retin Eye Res. 1999; 18(1):39-57.

3. Sample PA, Johnson CA. Functional assessment of glaucoma J Glaucoma. 2001;10(5 Suppl 1):S49-S52.

4. Sample PA, Medeiros FA, Racette L, et al. Identifying glaucomatous vision loss with visual-function-specific perimetry in the diagnostic innovations in glaucoma study. Invest Ophthalmol Vis Sci. 2006;47(8):3381-3889.

5. Jampel HD, Singh K, Lin SC, et al. Assessment of visual function in glaucoma: a report by the American Academy of Ophthalmology. Ophthalmology. 2011;118(5):986-1002.

6. Perry VH, Cowey A. Retinal ganglion cells that project to the superior colliculus and pretectum in the macaque monkey. Neuroscience. 1984; 12(4):1125-1137.

7. Yucel YH, Zhang Q, Weinreb RN, Kaufman PL, Gupta N. Effects of retinal ganglion cell loss on magno-, parvo-, koniocellular pathways in the lateral geniculate nucleus and visual cortex in glaucoma. Prog Retin Eye Res. 2003;22(4):465-481.

8. Gupta N, Ang LC, Noel de Tilly L, Bidaisee L, Yucel YH. Human glaucoma and neural degeneration in intracranial optic nerve, lateral geniculate nucleus, and visual cortex. Br J Ophthalmol. 2006;90(6): 674-678.

9. Duncan RO, Sample PA, Weinreb RN, Bowd C, Zangwill LM. Retinotopic organization of primary visual cortex in glaucoma: comparing fMRI measurements of cortical function with visual field loss. Prog Retin Eye Res. 2007;26(1):38-56.

10. Garaci FG, Bolacchi F, Cerulli A, et al. Optic nerve and optic radiation neurodegeneration in patients with glaucoma: in vivo analysis with 3-T diffusion-tensor MR imaging. Radiology. 2009;252(2):496-501.

11. Boucard CC, Hernowo AT, Maguire RP, et al. Changes in cortical grey matter density associated with long-standing retinal visual field defects. Brain. 2009;132(Pt 7):1898-1906.

12. Gupta N, Greenberg G, de Tilly LN, Gray B, Polemidiotis M, Yucel YH Atrophy of the lateral geniculate nucleus in human glaucoma detected by magnetic resonance imaging. Br J Ophthalmol. 2009;93(1):56-60. 
13. Gupta N, Yucel YH. Glaucoma as a neurodegenerative disease. Curr Opin Ophthalmol. 2007;18(2):110-114.

14. YucelY, Gupta N. Glaucoma of the brain: a disease model for the study of transsynaptic neural degeneration. Prog Brain Res. 2008;173:465-478.

15. Yucel YH, Zhang Q, Gupta N, Kaufman PL, Weinreb RN. Loss of neurons in magnocellular and parvocellular layers of the lateral geniculate nucleus in glaucoma. Arch Ophthalmol. 2000;118(3):378-384.

16. Saslow MG. Effects of components of displacement-step stimuli upon latency for saccadic eye movement. J Opt Soc Am. 1967;57(8): 1024-1029.

17. Munoz DP, Schall JD. Concurrent, distributed control of saccade initiation in the frontal eye field and superior colliculus. In: Hall WC, Moschovakis A, editors. The superior colliculus: new approaches for studying sensorimotor integration. Boca Raton, FL: CRC Press; 2004: 34-52.

18. Warabi T, Kase M, Kato T. Effect of aging on the accuracy of visually guided saccadic eye movement. Ann Neurol. 1984;16(4):449-454.

19. Fischer B, Weber H, Biscaldi M, Aiple F, Otto P, Stuhr V. Separate populations of visually guided saccades in humans: reaction times and amplitudes. Exp Brain Res. 1993;92(3):528-541.

20. Botzel K, Rottach K, Buttner U. Normal and pathological saccadic dysmetria. Brain. 1993;116(Pt 2):337-353.

21. Pitt MC, Rawles JM. The value of measuring saccadic eye movement in the investigation of non-compressive myelopathy. J Neurol Neurosurg Psychiatry. 1989;52(10):1157-1161.

22. Sharpe JA, Zackon DH. Senescent saccades. Effects of aging on their accuracy, latency and velocity. Acta Otolaryngol. 1987;104(5-6): 422-428.

23. Ober JK, Przedpelska-Ober E, Gryncewicz W, et al. Handheld system for ambulatory measurement of saccadic durations of neurological patients. In: Gajda J, editor. Modelling and measurement in medicine. Warsaw, Poland: Komitet Biocybernityki i Inzyneierii Biomedycznej PAN; 2003:187-198.

24. Pierrot-Deseilligny C, Rivaud S, Gaymard B, Agid Y. Cortical control of reflexive visually-guided saccades. Brain. 1991;114(Pt 3): 1473-1485

25. Michell AW, Xu Z, Fritz D, et al. Saccadic latency distributions in Parkinson's disease and the effects of L-dopa. Exp Brain Res. 2006; 174(1):7-18.

26. Rivaud S, Muri RM, Gaymard B, Vermersch AI, Pierrot-Deseilligny C. Eye movement disorders after frontal eye field lesions in humans. Exp Brain Res. 1994;102(1):110-120.

27. Antoniades CA, Altham PM, Mason SL, Barker RA, Carpenter R. Saccadometry: a new tool for evaluating presymptomatic Huntington patients. Neuroreport. 2007;18(11):1133-1136.

28. Pearson BC, Armitage KR, Horner CW, Carpenter RH. Saccadometry: the possible application of latency distribution measurement for monitoring concussion. Br J Sports Med. 2007;41(9):610-612.

29. Brigell MG, Goodwin JA, Lorance R. Saccadic latency as a measure of afferent visual conduction. Invest Ophthalmol Vis Sci. 1988;29(8): 1331-1338

30. Reulen JP. Latency of visually evoked saccadic eye movements. II. Temporal properties of the facilitation mechanism. Biol Cybern. 1984; 50(4):263-271.

31. Reilly JL, Lencer R, Bishop JR, Keedy S, Sweeney JA. Pharmacological treatment effects on eye movement control. Brain Cogn. 2008;68(3): $415-435$.

Eye and Brain

\section{Publish your work in this journal}

Eye and Brain is an international, peer-reviewed, open access journal focusing on clinical and experimental research in the field of neuro-ophthalmology. All aspects of patient care are addressed within the journal as well as basic research. Papers covering original research, basic science, clinical and epidemiological studies, reviews and Submit your manuscript here: http://www.dovepress.com/eye-and-brain-journal
32. Munoz DP, Broughton JR, Goldring JE, Armstrong IT. Age-related performance of human subjects on saccadic eye movement tasks. Exp Brain Res. 1998;121(4):391-400.

33. Shafiq-Antonacci R, Maruff P, Whyte S, Tyler P, Dudgeon P, Currie J. The effects of age and mood on saccadic function in older individuals. J Gerontol B Psychol Sci Soc Sci. 1999;54(6):P361-P368.

34. Irving EL, Steinbach MJ, Lillakas L, Babu RJ, Hutchings N. Horizontal saccade dynamics across the human life span. Invest Ophthalmol Vis Sci. 2006;47(6):2478-2484.

35. Sparks D, Rohrer WH, Zhang Y. The role of the superior colliculus in saccade initiation: a study of express saccades and the gap effect. Vision Res. 2000;40(20):2763-2777.

36. Fischer B, Ramsperger E. Human express saccades: extremely short reaction times of goal directed eye movements. Exp Brain Res. 1984; 57(1):191-195

37. Mays LE, Sparks DL. Dissociation of visual and saccade-related responses in superior colliculus neurons. J Neurophysiol. 1980;43(1): 207-232.

38. Schiller PH, Stryker M, Cynader M, Berman N. Response characteristics of single cells in the monkey superior colliculus following ablation or cooling of visual cortex. J Neurophysiol. 1974;37(1):181-194.

39. Abel PL, O'Brien BJ, Lia B, Olavarria JF. Distribution of neurons projecting to the superior colliculus correlates with thick cytochrome oxidase stripes in macaque visual area V2. J Comp Neurol. 1997;377(3): 313-323.

40. Parisi V. Impaired visual function in glaucoma. Clin Neurophysiol. 2001;112(2):351-358.

41. Rodarte C, Hood DC, Yang EB, et al. The effects of glaucoma on the latency of the multifocal visual evoked potential. $\mathrm{Br} J$ Ophthalmol. 2006;90(9):1132-1136.

42. Sehi M, Grewal DS, Goodkin ML, Greenfield DS. Reversal of retinal ganglion cell dysfunction after surgical reduction of intraocular pressure. Ophthalmology. 2010;117(12):2329-2336.

43. Raybourn MS, Keller EL. Colliculoreticular organization in primate oculomotor system. J Neurophysiol. 1977;40(4):861-878.

44. Buttner-Ennever JA, Henn V. An autoradiographic study of the pathways from the pontine reticular formation involved in horizontal eye movements. Brain Res. 1976;108(1):155-164.

45. Schiller PH, Sandell JH, Maunsell JH. The effect of frontal eye field and superior colliculus lesions on saccadic latencies in the rhesus monkey. J Neurophysiol. 1987;57(4):1033-1049.

46. Severt WL, Maddess T, Ibbotson MR. Employing following eye movements to discriminate normal from glaucoma subjects. Clin Experiment Ophthalmol. 2000;28(3):172-174.

47. Tong J, Wang J, Sun F. Dual-directional optokinetic nystagmus elicited by the intermittent display of gratings in primary open-angle glaucoma and normal eyes. Curr Eye Res. 2002;25(6):355-362.

48. Geruschat DR, Hassan SE, Turano KA, Quigley HA, Congdon NG. Gaze behavior of the visually impaired during street crossing. Optom Vis Sci. 2006;83(8):550-558.

49. Crabb DP, Smith ND, Rauscher FG, et al. Exploring eye movements in patients with glaucoma when viewing a driving scene. PLoS One. 2011;5(3):e9710.

50. Haymes SA, Leblanc RP, Nicolela MT, Chiasson LA, Chauhan BC. Risk of falls and motor vehicle collisions in glaucoma. Invest Ophthalmol Vis Sci. 2007;48(3):1149-1155.

evaluations, guidelines, expert opinion and commentary, case reports and extended reports are welcome. The manuscript management system is completely online and includes a very quick and fair peer-review system, which is all easy to use. Visit http://www.dovepress.com/ testimonials.php to read real quotes from published authors. 